\title{
Long-term performance of visual and electronic identification devices in dairy goats
}

\author{
S. Carné, ${ }^{*}$ G. Caja, ${ }^{* 1}$ J. J. Ghirardi, ${ }^{2}$ and A. A. K. Salama*† \\ ${ }^{*}$ Grup de Recerca en Remugants, Departament de Ciència Animal i dels Aliments, Universitat Autònoma de Barcelona, 08193 Bellaterra, Spain \\ †Sheep and Goat Research Department, Animal Production Research Institute, 12311 Dokki, Giza, Egypt
}

\begin{abstract}
Dairy goat kids born during a 3 -yr period $(\mathrm{n}=97)$ and their mothers $(n=29)$ were used for a long-term evaluation of the performance of 9 types of identification (ID) devices. Kids wore multiple ID devices: visual ear tags (V1, tip-tag, $\mathrm{n}=47$; V2, official, $\mathrm{n}=50$ ), electronic ear tags (E1, button-button, $\mathrm{n}=46$; E2, flag-button, $\mathrm{n}$ $=46$ ), electronic rumen boluses (B1, mini-bolus $14 \mathrm{~g}, \mathrm{n}$ $=92$; $\mathrm{B} 2$, mini-bolus $20 \mathrm{~g}, \mathrm{n}=28$; B3, standard bolus $75 \mathrm{~g}, \mathrm{n}=34)$ and glass-encapsulated transponders injected in the forefeet $(\mathrm{T} 1,15 \mathrm{~mm}, \mathrm{n}=75 ; \mathrm{T} 2,12 \mathrm{~mm}$, $\mathrm{n}=100)$. Visual ear tags were applied at birth and removed in yearlings, whereas electronic ear tags were applied after bolusing with B1 $(6.7 \mathrm{~kg} \mathrm{BW}$ and $30 \mathrm{~d}$, on average); B2 were administered in the event of a B1 loss, and B3 in case of a B2 loss and in goat does. At d 60 of age, kids were allocated into 2 groups to evaluate the effects of rearing system on ID. Treatments were: weaned $(\mathrm{n}=46)$, and not weaned $(\mathrm{n}=46)$ where kids suckled a milk substitute until d 150. Readability of ID devices $(\mathrm{read} / \mathrm{readable} \times 100)$ was monitored from 1 to $3 \mathrm{yr}$ of age, depending on device and year of birth. Long-term readability was analyzed using a nonparametric survival analysis. A total of $3.3 \%$ infections and $6.5 \%$ tissue reactions were reported for electronic ear tags, but ears were fully healed in yearlings. Weaning numerically reduced B1 losses at d 150 (weaned, 84.8\% vs. not weaned, $73.3 \%$ ). Readability of visual ear tags in yearlings (V1, 82.9\%; V2, 94.0\%) was lower than for electronic ear tags (E1 and E2, 100\%). Mini-bolus readability in yearlings did not differ by type (B1, 71.4\%; B2, 84.6\%) or with visual ear tags. No effect of inject type was reported (T1, 92.0\%; T2, 96.0\%). Survival analysis after yr 3 gave the greatest readability value for E1 (100\%), which did not differ from B3 (96.8\%). The lowest readability was estimated for B1 (66.3\%),
\end{abstract}

\footnotetext{
Received July 24, 2008.

Accepted November 4, 2008.

${ }^{1}$ Corresponding author: gerardo.caja@uab.cat

${ }^{2}$ Current address: Rumitag, Esmeragda 19-21 Sobreàtic, 08950 Esplugues de Llobregat, Barcelona, Spain.
}

followed by E2 (79.8\%), B2 (81.4\%), and T1 (90.4\%). In conclusion, button-button electronic ear tags and standard boluses were the more efficient devices under our conditions, their readability values being greater than injects, electronic mini-boluses, and visual and flag-button electronic ear tags. Transponders injected in the forefeet and mini-boluses used here are not recommended in practice. Further research on E1 and B3 electronic devices should be done in a higher number of goats to confirm the current results.

Key words: bolus, ear tag, electronic identification, goat

\section{INTRODUCTION}

Electronic identification of sheep and goats has become an important issue in the European Union since the publication of Regulation CE 21/2004 (recently amended by SANCO/1427/2008), which establishes a double identification (ID) system for replacement animals with both a plastic ear tag and a second device to be chosen by each member state. When the sheep and goat population within a member state is greater than 600,000 animals, the second means of ID must be a passive radio-frequency device. Double ID was expected to be mandatory in 2008 but has been put off until 2010, although it has been officially deployable since July 2005. In Spain, the electronic bolus has been used as the second means of ID since January 2006 (Real Decreto $947 / 2005)$.

Optimum retention of boluses in sheep and cattle has been achieved by optimizing their physical features (Caja et al., 1999; Fallon, 2001; Ghirardi et al., 2006). However, bolus retention in the case of goats has shown remarkable variability in practice, ranging from 89.7 to $99.6 \%$ (JRC, 2003; Capote et al., 2005; Pinna et al., 2006). That is why current Spanish legislation (Real Decreto $947 / 2005$ ) permits the use (under authorization) of transponders injected in the metacarpus (forefoot) in goats. Although injection to this body site may prevent carcass contamination, animals cannot be used for consumption. Little information is available on the comparison of injectable transponders, electronic ear 


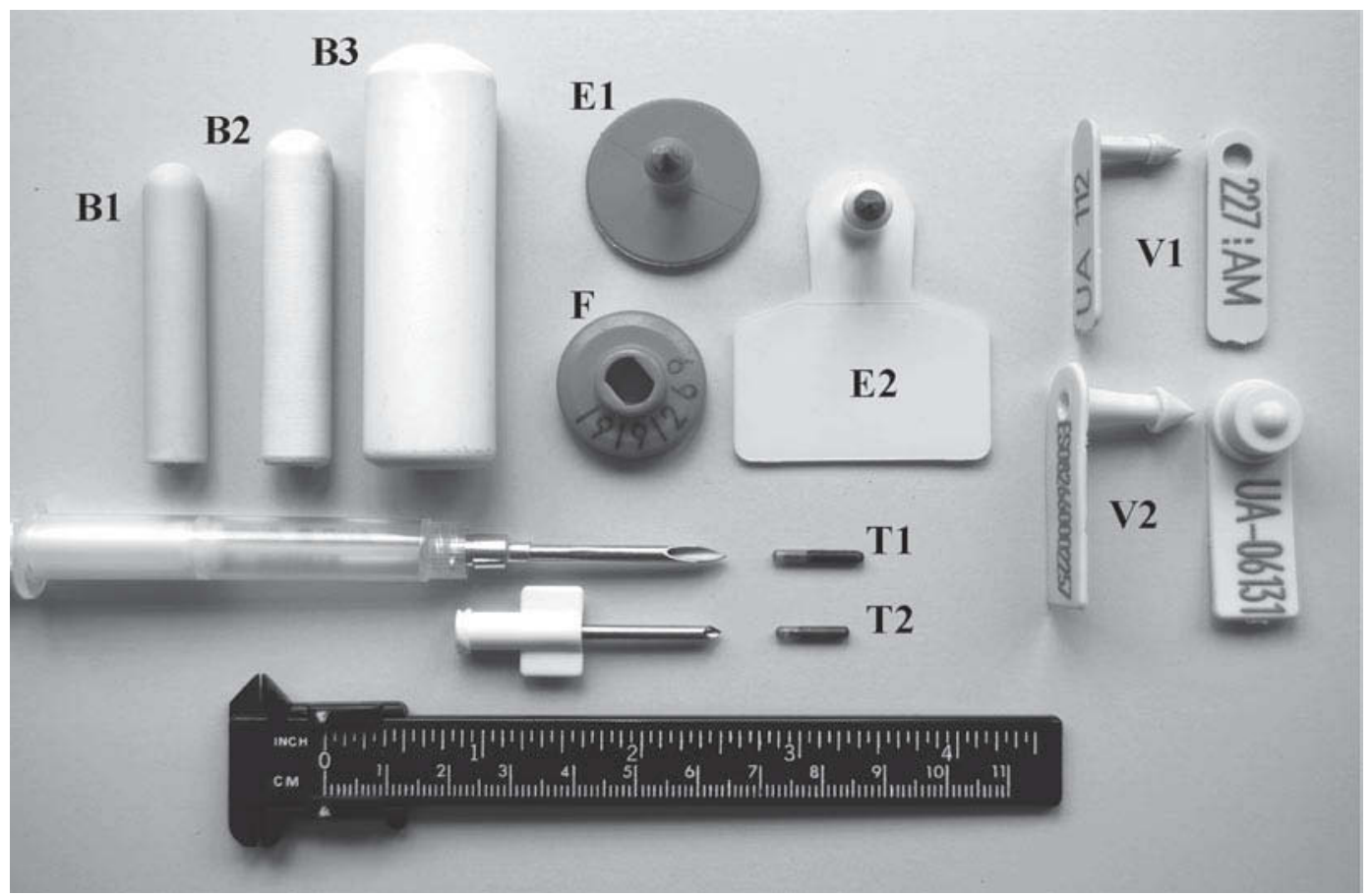

Figure 1. Electronic and visual devices used for the identification of dairy goats. V1 = tip-tag ear tag (Azasa-Allflex, Madrid, Spain); V2 $=$ official tamper-proof ear tag (Azasa-Allflex); B1 = mini-bolus $13.7 \mathrm{~g}$ and $51.0 \times 10.5 \mathrm{~mm}$ (Rumitag, Esplugues de LLobregat, Spain); B2 $=$ mini-bolus $20.1 \mathrm{~g}$ and $56.4 \times 10.5 \mathrm{~mm}$ (Rumitag); B3 = standard bolus $75 \mathrm{~g}$ and $68.2 \times 21.0 \mathrm{~mm}$ (Rumitag); E1 = ear tag made of plastic button male piece (Azasa-Allflex) and electronic button female piece (Allflex Europe, Vitré, France); E2 = ear tag made of plastic flag male piece (Azasa-Allflex) and electronic button female piece (Allflex Europe); T1 = injectable transponder $15 \times 2.1 \mathrm{~mm}$ (Avid Microchip España, Barcelona, Spain); T2 = injectable transponder $12 \times 2.1 \mathrm{~mm}$ (Cromasa, Berriozar, Spain).

tags, and boluses in goats. In contrast to goats, over 99\% retention has been achieved in lambs by using small size boluses (Garín et al., 2005; Ghirardi et al., 2007). No information is available on the use of electronic ID devices in replacement goat kids. The aim of this study was to investigate the long-term performance of visual and electronic ID devices applied in kids and dairy goats, as well as to evaluate the influence of rearing management conditions on the variability of the retention rate of small size electronic boluses.

\section{MATERIALS AND METHODS}

The experimental procedures and animal care conditions were approved by the Ethical Committee on Animal and Human Experimentation (Reference CEEAH 606/06) of the Universitat Autònoma de Barcelona. A total of 29 goat does and 97 goat kids of Murciano-Granadina dairy breed from the Experimental Farm of the Servei de Granges i Camps Experimentals (S1GCES), Universitat Autònoma de Barcelona, were used. Goat does were bred for an annual kidding season in the autumn and kidded during fall of $2004(\mathrm{n}=27), 2005$ $(\mathrm{n}=18)$, and $2006(\mathrm{n}=18)$, giving birth to 45,26 , and
26 kids, respectively. Kids were under study for 3, 2, or $1 \mathrm{yr}$ depending on the year of birth.

\section{Visual Identification}

Each kid was identified at birth with 1 visual ear tag applied on the left ear. Two types of rectangular visual ear tags made of plastic (Figure 1) from the same manufacturer (Azasa-Allflex, Madrid, Spain) were used; ear tags features (weight, flag dimensions and pin dimensions) were "tip-tag" ear tag (V1; $1.4 \mathrm{~g}$, $35.5 \times 9.3 \mathrm{~mm}, 15.5 \times 3.9 \mathrm{~mm}$; opened female piece; $\mathrm{n}$ $=47$ ) commonly used by the farmers for their low cost; and, official tamperproof ear tag (V2; $2.8 \mathrm{~g}, 40 \times 14.5$ $\mathrm{mm}, 22 \times 5 \mathrm{~mm}$; closed female piece; $\mathrm{n}=50$ ) made to fulfill the new requirements of the European Union Regulation 21/2004. Both V1 and V2 ear tags were considered temporary ID and were removed at 12 mo of age when yearling kids joined the breeding herd. All ear tags were printed with both a serial animal number $(7$ digits) and the holding number (14 digits) as required by Regulation $21 / 2004$.

Goat does wore 2 flag plastic ear tags of large size (48 $\times 38 \mathrm{~mm}$, yellow color; Azasa-Allflex) in the left ear. 
These large ear tags were manually marked with individual codes of 3 digits $(27 \times 10 \mathrm{~mm}$ each $)$ with black plastic ink (Allflex Tag Pen, Dallas, TX) and were used for milk recording (Ait-Saidi et al., 2008).

\section{Rearing Treatments and Management}

Kids were separated from their mothers in the first $8 \mathrm{~h}$ after birth, moved to straw-bedded pens $\left(0.5 \mathrm{~m}^{2}\right.$ per kid) and fed colostrum 3 times a day until d 3 . After d 3, kids were provided ad libitum milk replacer (CP, 23.8\%; ether extract, 25.0\%; crude fiber, 0.3\%; ash, $6.6 \%$; F 463, Sofivo, Condé sur Vire, France) in a concentration of $150 \mathrm{~g} / \mathrm{L}$ until wk 8 by using an automatic milk dispenser (Model M-E250, Industrias J.R., Valdelafuente, Spain). From wk 3 of age, kids were also fed ad libitum with barley straw and a commercial concentrate (CP, 17.4\%; ether extract, 3.3\%; crude fiber, 4.1\%; ash, 5.8\%; O-118-G, La Gironina, Sant Gregori, Spain). Kids had free access to water as well. To evaluate the effect of rearing management on losses of ID devices administered at early ages, kids of $60 \pm 3.1$ $\mathrm{d}(10.2 \pm 0.2 \mathrm{~kg}$ BW) were allocated into 2 balanced groups according to $\mathrm{BW}$ and randomly assigned to 2 experimental rearing treatments: weaned $(\mathbf{W} ; \mathrm{n}=46)$, where kids were weaned with no transition period; and not weaned $(\mathbf{N W} ; \mathrm{n}=46)$, where each kid received a daily $(1700 \mathrm{~h})$ supplement of approximately $1 \mathrm{~L}$ of a 1:1 dilution of goat milk in warm water $\left(35^{\circ} \mathrm{C}\right)$ until 5 mo of age. Diluted milk supplement was administered by using buckets (9 L) with rubber teats, as described when attempting to maintain an active esophageal groove reflex (Ørskov et al., 1970). This conditioned reflex is a physiological mechanism of suckling ruminants to allow milk to by-pass the reticulorumen and reach the abomasum. Rubber nipples were placed at approximately $25 \mathrm{~cm}$ from the ground to allow for a natural position of suckling kids; that is, with the head and cranial esophagus in a lower position with respect to thoracic esophagus and forestomachs.

Concentrate was gradually replaced, from 2 to 4 mo of age, by whole barley grain and alfalfa pellets (1:1) ad libitum. At the age of 4 mo, kids passed to a semiconfined system, grazing $6 \mathrm{~h}$ daily (0900 to $1500 \mathrm{~h}$ ) in cultivated Italian ryegrass pasture and supplemented with a dehydrated mixture of whole-plant corn and alfalfa hay (1:1) fed ad libitum, and a commercial concentrate (CP, $17.5 \%$; ether extract, $3.8 \%$; crude fiber, $4.0 \%$; ash, $7.1 \% ; 1.53$ Mcal of $\mathrm{NE}_{\mathrm{L}} / \mathrm{kg}$ ) according to the physiological stage. At the age of 18 mo, 47 (51\%) animals were sold to 2 nearby herds and they continued to be monitored at least every 3 mo until the end of the study, or until death or slaughter.
In addition, 29 adult goats were used as a control for long-term retention of ID devices. Animals that died during the study were sent to the Pathology Service of the Universitat Autònoma de Barcelona for necropsy.

\section{Electronic Identification Devices and Administration Procedures}

Ruminal Boluses. Three types of cylindrical boluses (Rumitag, Esplugues de Llobregat, Spain) were used (Figure 1). Boluses were made of nontoxic, nonporous, and highly dense ceramic materials and their features were as follows [material, weight, length $\times$ o.d., and specific gravity]: bolus 1 (B1; zirconia, $13.7 \mathrm{~g}, 51 \times 10$ $\mathrm{mm}$, and $3.5 ; \mathrm{n}=92)$, bolus 2 (B2; zirconia, $20.1 \mathrm{~g}, 56$ $\times 11 \mathrm{~mm}$, and $3.9 ; \mathrm{n}=28)$, and bolus 3 (B3; alumina, $75.0 \mathrm{~g}, 68.2 \times 21.0 \mathrm{~mm}$, and $3.4 ; \mathrm{n}=34$ ). The first 2 types were small boluses specially designed to be administered to lambs and kids at early ages. The third type was a standard-size bolus previously used for cattle, sheep, and goats (JRC, 2003; Capote et al., 2005; Pinna et al., 2006) and used as a control. Each bolus contained a half-duplex (HDX), read-only, glass-encapsulated transponder of $32 \times 3.8 \mathrm{~mm}$ (Ri-Trp-RR2B-06, Tiris, Almelo, the Netherlands). In kids born after July 2005, transponders included the country (Spain, 724), species (sheep and goat, 04) and the autonomous community (Catalonia, 09) codes and a 10-digit serial number, according to the current Spanish legislation (Real Decreto 947/2005) and in agreement with ISO 11784 and 11785 standards on animal electronic ID (ISO, 1996a,1996b). For the rest of the animals, ISO transponders with the ICAR (2008) official manufacturer code (Rumitag, 964) and a 12-digit serial number were used.

For B1, to determine the minimum age and BW at safe bolusing, application was attempted on kids older than $15 \mathrm{~d}$ of age twice weekly. Boluses were administered by a trained operator by using an adapted balling gun (Rumitag). For bolus administration, kids were restrained between the operator's legs, holding the animal caudally to its shoulder blades. Then, the operator bent down and introduced the balling gun laterally into the animal's mouth while holding with the other hand its lower jaw at the region without teeth (diastema). The bolus was released into the bottom of the oropharyngeal cavity (base of the tongue) to stimulate the involuntary swallowing reflex, as described by Caja et al. (1999). If swallowing difficulties were observed, the bolus was expelled by means of an upward external massage on the throat and administration was delayed until the following bolusing session. To solve difficulties in the passage of a swallowed bolus through the esophagus tract, a plastic probe $($ length $\times$ o.d., $500 \times 10 \mathrm{~mm})$ was 
prepared and used if necessary to gently push the bolus into the reticulorumen as previously done by Garín et al. (2005) and Ghirardi et al. (2007) in suckling lambs. The B2 bolus was administered in case of a loss of a B1 bolus by using the same procedures described above. Likewise, B3 boluses were administered in the event of a B2 loss. The B3 were administered by 1 operator and 1 assistant when animals had a BW greater than $20 \mathrm{~kg}$, as indicated by Caja et al. (1999). Adult goats used as a control were identified with B3 boluses when yearlings, before joining the rest of the herd; one goat was rebolused with B3 before starting the study.

Electronic Ear Tags. Along with the B1 bolus administration, each kid was tagged with an electronic ear tag (Figure 1) on the right ear. One type of ear tag button female piece (F; weight $4.1 \mathrm{~g}$, o.d. $24 \mathrm{~mm}$, and height $11 \mathrm{~mm}$; Allflex Europe, Vitré, France; n = 92) containing an HDX transponder was used. Transponder serial numbers included the manufacturer code (Allflex, 982) and worked in accordance with ISO standards (ISO, 1996a,b). Two types of male pieces were used: E1 button type (Azasa-Allflex, Madrid, Spain; weight $1.8 \mathrm{~g}$, button o.d. $28.5 \mathrm{~mm}$, pin length $\times$ o.d. $20.5 \times 5.5$ $\mathrm{mm} ; \mathrm{n}=46$ ) and $\mathbf{E 2}$ flag type (Azasa-Allflex; $3 \mathrm{~g}$; flag length $\times$ width $48.5 \times 42 \mathrm{~mm}$, pin length $\times$ o.d. $20.5 \times$ $5.5 \mathrm{~mm} ; \mathrm{n}=46)$. Ear tags were applied to the middle of the ear at one third from the ear base, using tagger pliers recommended by the manufacturer (Universal Total Tagger, Allflex Europe); the F piece was placed on the internal side of the ear.

Injectable Transponders. A total of 175 fullduplex (FDX-B) read-only and glass-encapsulated transponders from 2 manufacturers were injected subcutaneously in the forefeet of 91 goat kids at $90 \mathrm{~d}$ of age. Transponders were (Figure 1): transponder 1(T1; Avid Microchip España, Barcelona, Spain; length $\times$ o.d. $15 \times 2.1 \mathrm{~mm} ; \mathrm{n}=75)$ and transponder $2(\mathbf{T} 2$; Cromasa, Berriozar, Spain; $12 \times 2.1 \mathrm{~mm} ; \mathrm{n}=100$ ). Serial numbers of transponders followed ISO standards (ISO, 1996a, b) and included the manufacturer code (Avid, 977; Cromasa, 953).

Injections of $\mathrm{T} 1$ were done using sterile single-use disposable syringes (Avid Microchip España) equipped with 31- $\times 2.8-\mathrm{mm}$ needles with a bevel length of $10.3 \mathrm{~mm}$ (Figure 1). Injections of T2 were done using a single-shot injector (Cromasa) with multiple-use $23-\times 2.5-\mathrm{mm}$ needles with a bevel length of $3 \mathrm{~mm}$. In this case, each needle was replaced after 20 to 25 injections. The T2 were presented in 20-unit dispensers (Identron-GT 212; Cromasa) and individually covered in an iodine solution; each transponder was charged by introducing the injector needle into the transponder dispenser, resulting in the needle being immersed in the iodine solution before each injection. To perform the injections, 1 assistant restrained the animals on its back on a V-shaped restraining table, stretching out their extremities. The operator then held the forefoot and injected the transponder subcutaneously in a downward proximo-distal direction into the rear face of the metacarpal area, resulting in the transponder being placed at 1 to $2 \mathrm{~cm}$ over the proximal sesamoid bones (ossa sesamoidea proximalia). A gentle external pressure with a finger was exerted on the injection site when withdrawing the needle to diminish the backward movement of transponders during this process. After injection, a topical antibiotic (Veterin Tecnicol, Laboratorios Intervet, Salamanca, Spain) was sprayed on the injection site. All injections were performed by previously trained operators.

\section{Monitoring of Kids and Identification Devices}

Kids were weighed weekly until $60 \mathrm{~d}$ of age by using a portable scale with an accuracy of $10 \mathrm{~g}$ (FX-31, Allflex NZ, Palmerston, New Zealand). Kids were thereafter weighed every second week until $150 \mathrm{~d}$ old by using a Tru-Test AG 500-02 (Pakuranga, Auckland, New Zealand) electronic scale with an accuracy of $100 \mathrm{~g}$. Electronic devices were read in static conditions (animals restrained) by using ISO hand-held transceivers (Gesreader 2S, Rumitag) which were able to read ISO HDX and FDX-B transponders at a minimum distance of 12 and $20 \mathrm{~cm}$ for ear tags and boluses, respectively, as specified in the technical guidelines for the implementation of European Regulation 21/2004. Each electronic device was read immediately before and after administration to check possible breakages or electronic failures during administration procedures. Readings were performed with the reader at a close distance to the device being checked to avoid interferences with other transponders applied in the same animal. At postadministration readings, individual kid data was typed and stored into the reader. For the boluses, a directional caudo-cranial sweep on both sides of abdomen area was performed with the reader to check the proper descent of bolus into the reticulorumen. Age and BW at administration of ID devices were registered as well as time required for administration of boluses and injectable transponders. Any incidents during administration procedures were also recorded.

Readings were taken at every weighing session under static conditions, until $150 \mathrm{~d}$ of age. From 5 to 18 mo of age all devices were read and checked monthly, and thereafter every 2 mo. In addition to losses, ear tags were monitored for electronic failure and damage (breakage, signs of nibbling, etc), as well as kid healthiness (hair appearance, growth, normal behavior, etc) and ear tissue reactions. When evaluating the performance of 
injectable transponders, differentiation among losses, breakages, and electronic failures was determined by palpation as described by Conill et al. (2000), and an electronic failure was assumed when the transponder was deemed neither lost nor broken. Boluses applied in adult goats (B3) were read with the same regularity as devices applied in kids.

Performance of ID devices was expressed as readability, being:

$$
\begin{gathered}
\text { Readability }=(\text { no. of read devices } / \\
\text { no. of readable devices }) \times 100 .
\end{gathered}
$$

Unreadable devices included losses, failures, and devices with damage that made them unreadable.

Dimensions of a total of $50 \mathrm{~F}$ pieces and 50 male pieces $(\mathrm{E} 1, \mathrm{n}=25 ; \mathrm{E} 2, \mathrm{n}=25)$ of the electronic ear tags were measured by using an electronic digital caliper (accuracy $=0.03 \mathrm{~mm}$; Shaodong Feiyue Hardware Tools Factory, Yiwu, China). The mechanical resistance of the locking system of these devices was measured by suspending a ballast and applying progressive weights (0.1 kg) until achieving $40 \mathrm{~kg}$.

\section{Statistical Analyses}

Least squares means of age and BW at administration of devices were obtained with the GLM procedure of SAS (v. 9.1, SAS Inst. Inc., Cary, NC). Factors considered were type of ID device, year of birth, and the interaction type of ID device $\times$ year of birth. Nonsignificant $(P>0.20)$ effects were removed from the model. Data on physical features and resistance of the locking system of electronic ear tags were analyzed with the GLM procedure of SAS.

Losses, electronic failures, and readability of ID devices were analyzed with the CATMOD procedure of SAS on the basis of the categorical nature of these variables. A logit model with an estimation method of maximum likelihood (Cox, 1970) was used, evaluating the effects of type of ID device, year of birth, and the interaction type of ID device $\times$ year of birth. For the $\mathrm{B} 1$ and B2 bolus, effect of rearing treatment (W vs. NW) was also included. Significance was declared at $P$ $<0.05$ and interactions that were not significant $(P>$ $0.20)$ were removed from the final models. Statistical analyses did not allow for comparisons with ID devices with no registered losses (100\% readability).

For the analysis of readability at the end of yr 3, the Kaplan-Meier nonparametric survival analysis was considered preferable to the logit model to avoid the possible bias produced by the low number of animals monitored. A log-rank test of equality across strata (ID devices) was performed with the LIFETEST procedure of SAS. This analysis permitted the comparison of the longitudinal readability of ID devices throughout the entire period of study without excluding right censored data (data from animals that left the study before a device failed), according to Cantor (2003) and Kleinbaum and Klein (2005), as well as the Kaplan-Meier estimates of readability for each type of device used. Survival monitoring started at device administration and, as continuous goat monitoring was not possible, time of device unreadability was registered as intervalcensored data. In addition to Kaplan-Meier's readability estimates, survival curves for each ID device were also produced.

\section{RESULTS AND DISCUSSION}

\section{Administration of Identification Devices}

Total number of ID devices and administration records are shown in Table 1. Both V1 and V2 visual ear tags were inserted in kids of $1 \mathrm{~d}$ of age without incidents. Five kids $(5.2 \%)$ died during the first 2 wk of suckling before being assigned to the extended rearing treatments, and 5 more kids $(5.2 \%)$ died during yr 1 of the long-term study. Overall yearling mortality was $10.3 \%$, which was lower than the average values reported under similar management conditions (15 to 20\%; Daza, 2004). No relationship was established between kid casualties and the ID system used despite the long-term presence of boluses in the forestomachs and of injectable transponders in the pastern. The data from kids that died $(\mathrm{n}=5)$ before being identified with electronic ID devices were eliminated from the study and only 92 kids were used.

Electronic Boluses. Four cases (4.3\%) of bolus blockage into the esophagus occurred during administration of B1 in 1 mo of age suckling kids (Table 1). Within a few minutes of bolusing these kids showed profuse foamy sialorrhea along with nasal discharge, dyspnea, and apathy. Similar findings have also been reported when studying the minimum age and $\mathrm{BW}$ at mini-bolus administration in fattening lambs (Ghirardi et al., 2007). External palpation and directional caudocranial readings with a hand-held reader were carried out to confirm the bolus blockage. The esophageal probe was used to gently push the bolus into the reticulorumen as indicated by Garín et al. (2005) and Ghirardi et al. (2007). Affected kids fully recovered and no further incidents or secondary effects were reported. Safe bolus administration at early ages mainly depends on the anatomical development of the pharynx and esophagus and on the dimensions (length and o.d.) of boluses used. With regard to kid anatomical development, BW seems 
Table 1. Identification devices ${ }^{1}$ administered to kids $(\mathrm{n}=97)$ and adult dairy goats $(\mathrm{n}=29)$ during a 3 -yr study

\begin{tabular}{|c|c|c|c|c|c|c|c|c|c|}
\hline Item & \multicolumn{2}{|c|}{ Visual ear tags ${ }^{2,3}$} & \multicolumn{3}{|c|}{ Electronic boluses } & \multicolumn{2}{|c|}{ Electronic ear tags ${ }^{4}$} & \multicolumn{2}{|c|}{ Injectable transponders } \\
\hline $\begin{array}{l}\text { Devices, } \mathrm{n} \\
\text { Administration records }\end{array}$ & 47 & 50 & 92 & 28 & 34 & 46 & 46 & 75 & 100 \\
\hline Age, d & 1 & 1 & $30 \pm 1$ & $171 \pm 26$ & Adult & $30 \pm 1$ & $30 \pm 1$ & $90 \pm 4$ & $92 \pm 4$ \\
\hline $\mathrm{BW}, \mathrm{kg}$ & $2.1 \pm 0.1^{\mathrm{a}}$ & $2.3 \pm 0.1^{\mathrm{a}}$ & $6.8 \pm 0.1^{\mathrm{b}}$ & $19.3 \pm 3.9^{\mathrm{c}}$ & $43.6 \pm 1.2^{\mathrm{d}}$ & $6.9 \pm 0.1^{\mathrm{b}}$ & $6.8 \pm 0.1^{\mathrm{b}}$ & $14.6 \pm 0.3^{\mathrm{c}}$ & $15.1 \pm 0.3^{\mathrm{c}}$ \\
\hline Time, s & - & - & $28 \pm 1^{\mathrm{a}}$ & $26 \pm 1^{\mathrm{a}}$ & - & - & - & $34 \pm 1^{\mathrm{b}}$ & $37 \pm 1^{\mathrm{b}}$ \\
\hline
\end{tabular}

${ }^{\mathrm{a}-\mathrm{d}}$ Within a row, values with different superscripts differ $(P<0.05)$.

${ }^{1} \mathrm{~V} 1=$ tip-tag ear tag (Azasa-Allflex, Madrid, Spain); V2 = official tamper-proof ear tag (Azasa-Allflex); B1 = mini-bolus $13.7 \mathrm{~g}$ and $51.0 \times 10.5$ mm (Rumitag, Esplugues de LLobregat, Spain); B2 = mini-bolus $20.1 \mathrm{~g}$ and $56.4 \times 10.5 \mathrm{~mm}$ (Rumitag); B3= standard bolus $75 \mathrm{~g}$ and $68.2 \times$ $21.0 \mathrm{~mm}$ (Rumitag); E1 = ear tag made of plastic button male piece (Azasa-Allflex) and electronic button female piece (Allflex Europe, Vitré, France); E2 = ear tag made of plastic flag male piece (Azasa-Allflex) and electronic button female piece (Allflex Europe); T1 = injectable transponder $15 \times 2.1 \mathrm{~mm}$ (Avid Microchip España, Barcelona, Spain); T2 = injectable transponder $12 \times 2.1 \mathrm{~mm}$ (Cromasa, Berriozar, Spain).

${ }^{2}$ Applied on the left ear at $1 \mathrm{~d}$ of age.

${ }^{3}$ Five goat kids died during the first 2 wk of the suckling period.

${ }^{4}$ Applied on the right ear just after B1 administration.

${ }^{5}$ One goat kid died at $79 \mathrm{~d}$ of age because of pneumonia.

${ }^{6}$ Administered after detecting a B1 being lost.

${ }^{7}$ Administered after detecting a B2 being lost $(\mathrm{n}=5)$ as well as in adult goats $(\mathrm{n}=29)$.

${ }^{8}$ Boluses were blocked in the esophagus and gently pushed with a probe $(500 \times 10 \mathrm{~mm})$ to the reticulorumen without health consequences.

${ }^{9}$ Profuse bleeding in 3 ears which stopped within a few minutes, 3 more ears showed infection with purulent secretion that healed at 2 mo. Six more ears showed tissue reaction (swelling and irritation) to ear tags but fully recovered at 6 mo.

${ }^{10}$ Bleeding after injection without posterior infection.

${ }^{11}$ Bleeding after injection without posterior infection was observed and 1 kid more showed limping that recovered $1 \mathrm{~d}$ later.

to be more accurate than age to assess the threshold for the safe administration of boluses. The BW and age at which B1 administration was possible were $6.8 \mathrm{~kg}$ and $30 \mathrm{~d}$ on average (Table 1). Using the same bolus type, Ghirardi et al. (2007) reported a BW at administration of 8.6 and $9.6 \mathrm{~kg}$ in lambs of local and dairy breeds, respectively. Using standard boluses of $66 \times 20 \mathrm{~mm}(65$ g), Caja et al. (1999) recommended a BW greater than 20 and $25 \mathrm{~kg}$ for goats and sheep, respectively. Our results confirmed that boluses can be administered at an earlier age and lower BW in goats than in sheep.

A total of $19 \mathrm{~B} 1$ were lost by 5 mo of age (readability $79.1 \%$; Table 2) and were replaced by B2, which were administered at $14.9 \pm 0.3 \mathrm{~kg}$ of $\mathrm{BW}$ and $105 \pm 7 \mathrm{~d}$ on average. No administration incidents were observed at this time. In addition, another 7 and $2 \mathrm{~B} 1$ were lost and replaced by B2 by yr 1 and 3 of the experiment, respectively, with a total of $28 \mathrm{~B} 2$ boluses administered (Table 1 and 2). Time needed for bolus administration, reading, and recording of ID data into the reader did not differ between $\mathrm{B} 1$ and $\mathrm{B} 2$ boluses (Table 1; $P=$ $0.505)$ and was lower than that reported by Ghirardi et al. (2007) for mini-bolus administration in lambs; however, those authors included restraining time in the application time.

After 1 yr of age, yearling kids having lost B2 $(n=4)$ were administered B3 and no incidents were reported. Time for B3 administration was not recorded.
Electronic Ear Tags. Three cases (3.3\%) of profuse bleeding that stopped within a few minutes were observed after ear tag insertion. Whereas $90.2 \%$ of ears were completely healed at 2 mo after tagging, $3(3.3 \%)$ ears showed infection with purulent secretion and $6(6.5 \%)$ more ears showed a marked tissue reaction to the attached ear tags. Tissue reaction appeared as perceptible swelling of the ear and noticeable irritation under the ear tag but without bleeding or apparent signs of infection. Edwards et al. (2001) tested both plastic and metal ear tags in sheep and only reported the presence of tissue reaction to the metal tags. In our study, these findings remained apparent until 4 mo and then progressively decreased until eventually disappearing at 6 mo postapplication. Length of healing period did not affect the size of the hole made at ear tagging, although some cases of increased ear thickness and hair loss around the tagging hole were observed. Ear tag readability was not affected by the healing process.

Injectable Transponders. Size of injectable transponders was a relevant shortcoming for the injection in the rear metacarpal area of kids. Experiments carried out so far in this body site have evaluated the use of injectable transponders varying in length (12 to $15 \mathrm{~mm}$ ) and o.d. (2.1 to $3 \mathrm{~mm}$ ) in lambs and in adult sheep and goats (Abecia et al., 2004; MAPA, 2007). In our study, transponders of $15 \times 3 \mathrm{~mm}$ were anticipated to be too large to be used in kids and only $2.1 \mathrm{~mm}$ 
Table 2. Long-term performance of identification devices ${ }^{1}$ in kids $(n=97)$ and adult dairy goats $(n=29)$ during a 3-yr study

\begin{tabular}{|c|c|c|c|c|c|c|c|c|c|}
\hline Item & \multicolumn{2}{|c|}{ Visual ear tags ${ }^{2}$} & \multicolumn{3}{|c|}{ Electronic boluses } & \multicolumn{2}{|c|}{ Electronic ear tags ${ }^{3}$} & \multicolumn{2}{|c|}{ Injectable transponders } \\
\hline \multicolumn{10}{|l|}{ Birth to $5 \mathrm{mo}$ of age } \\
\hline Readable, $\mathrm{n}$ & 35 & 49 & 72 & 19 & - & 46 & 45 & 69 & 97 \\
\hline Readability, ${ }^{7} \%$ & $85.4^{\mathrm{ac}, \mathrm{x}}$ & $98.0^{\mathrm{bc}, \mathrm{y}}$ & $79.1^{\mathrm{a}}$ & 100 & - & 100 & 100 & $92.0^{\mathrm{cd}}$ & $97.0^{\text {bd }}$ \\
\hline \multicolumn{10}{|l|}{6 to $12 \mathrm{mo}$ of age } \\
\hline Readability, \% & $82.9^{\mathrm{ab}}$ & $94.0^{\mathrm{ac}}$ & $71.4^{\mathrm{b}}$ & $84.6^{\mathrm{ab}}$ & 100 & 100 & 100 & $92.0^{\mathrm{ac}}$ & $96.0^{\mathrm{c}}$ \\
\hline \multicolumn{10}{|l|}{1 to 2 yr of age } \\
\hline Previous, $n$ & - & - & 66 & 22 & 32 & 33 & 33 & 66 & 50 \\
\hline Administered, $\mathrm{n}$ & - & - & 0 & 2 & 1 & 0 & 0 & 0 & 0 \\
\hline Readable, n & - & - & 44 & 20 & 32 & 33 & 31 & 60 & 48 \\
\hline Readability, \% & - & - & $66.7^{\mathrm{a}}$ & $83.3^{\mathrm{ab}, \mathrm{x}}$ & $97.0^{\mathrm{b}}$ & 100 & $93.9^{\mathrm{b}}$ & $90.9^{\mathrm{b}}$ & $96.0^{\mathrm{b}, \mathrm{y}}$ \\
\hline
\end{tabular}

${ }^{\mathrm{a}-\mathrm{d}}$ Within a row, values with different superscripts differ $(P<0.05)$.

${ }^{\mathrm{x}, \mathrm{y}}$ Within a row, values with different superscripts differ $(P<0.10)$.

${ }^{1} \mathrm{~V} 1=$ tip-tag ear tag (Azasa-Allflex, Madrid, Spain); V2 = official tamper-proof ear tag (Azasa-Allflex); B1 = mini-bolus $13.7 \mathrm{~g}$ and $51.0 \times 10.5$ mm (Rumitag, Esplugues de LLobregat, Spain); B2 = mini-bolus $20.1 \mathrm{~g}$ and $56.4 \times 10.5 \mathrm{~mm}$ (Rumitag); B3= standard bolus $75 \mathrm{~g}$ and $68.2 \times$ $21.0 \mathrm{~mm}$ (Rumitag); E1 = ear tag made of plastic button male piece (Azasa-Allflex) and electronic button female piece (Allflex Europe, Vitré, France); E2 = ear tag made of plastic flag male piece (Azasa-Allflex) and electronic button female piece (Allflex Europe); T1 = injectable transponder $15 \times 2.1 \mathrm{~mm}$ (Avid Microchip España, Barcelona, Spain); T2 = injectable transponder $12 \times 2.1 \mathrm{~mm}$ (Cromasa, Berriozar, Spain).

${ }^{2}$ Applied on the left ear at $1 \mathrm{~d}$ of age, and removed in yearlings.

${ }^{3}$ Applied on the right ear just after B1 administration.

${ }^{4}$ One goat kid died at $79 \mathrm{~d}$ of age because of pneumonia.

${ }^{5}$ Administered after detecting a B1 being lost $(\mathrm{n}=28)$.

${ }^{6}$ Administered after detecting a B2 being lost $(n=5)$ as well as in adult goats $(n=29)$.

${ }^{7}$ Readability of ear tags included retention and reading (visual or electronic).

o.d. were used. Age and BW at which T1 and T2 were injected are shown in Table 1. Four (5.3\%) and $6(6 \%)$ cases of bleeding after injection were observed for $\mathrm{T} 1$ and T2, respectively. Only 1 case (1\%) of limping was observed after injecting a T2 transponder; the limping disappeared the following day with no treatment. No inflammation or signs of infection were observed and injection wounds totally healed within the following 2 wk. Time required for injection, reading, and animal data recording (Table 1 ) did not differ between $\mathrm{T} 1$ and T2 $(P=0.122)$ and averaged $36 \pm 1 \mathrm{~s}$. Abecia et al. (2004) reported values of injection time also ranging from 30 to $40 \mathrm{~s}$ in lambs and adult sheep, including restraining time but without taking into account time for reading and storing ID data.

\section{Effects of Kid Rearing on Readability of Identification Devices}

A total of 6 NW kids (13\%) refused to suckle the milk from buckets during the rearing treatments, and were bottle fed. Kid daily growth was greater in NW during the first 2 wk of treatment (data not shown) but $\mathrm{BW}$ at the end of the rearing treatments ( 5 mo of age) did not differ between groups (W, $18.2 \pm 0.4 \mathrm{~kg}$; NW, $18.6 \pm 0.6 \mathrm{~kg} ; P=0.826)$.

Regarding ID devices, 6 losses of V1 (14.6\%) were reported by the end of the rearing treatments. Ear tag losses occurred without producing split ears and were not related to year and rearing treatments $(P>0.05)$. No losses of V2 were observed during this period, most likely because of an improved design and the tamperproof closing system. Nevertheless, 1 (2.0\%) V2 showed severe damage caused by bites, and was unreadable. As a consequence, readability of V1 (85.4\%) and V2 $(98.0 \%)$ at 5 mo tended to differ $(P=0.053)$. No losses or failures were observed for E1 and E2 during the whole rearing period and readability for electronic ear tags was $100 \%$. Nevertheless, $4(8.7 \%)$ cases of damage to the flag piece of $\mathrm{E} 2$ were registered.

With regard to bolus readability, no differences between years were observed $(P=0.881)$ and annual 
Table 3. Effect of extending the suckling period until 5 mo of age on the readability of electronic mini-bolus ${ }^{1}$ in goat kids (values are averaged data for $3 \mathrm{yr})^{2}$

\begin{tabular}{|c|c|c|c|c|}
\hline \multirow[b]{2}{*}{ Bolus, $\mathrm{n}$} & \multicolumn{2}{|c|}{ Rearing treatment } & \multirow[b]{2}{*}{ Overall } & \multirow[b]{2}{*}{$P$-value } \\
\hline & Weaned & Not weaned $^{3}$ & & \\
\hline Administered & 46 & 45 & 91 & - \\
\hline Lost & 7 & 12 & 19 & - \\
\hline Read & 39 & 33 & 73 & - \\
\hline Readability, \% & 84.8 & 73.3 & 79.1 & 0.184 \\
\hline
\end{tabular}

data were joined. The anatomical changes produced in the reticulorumen during the esophageal groove reflex activation did not affect bolus retention in the suckling kids, although a numerically greater retention of B1 at 5 mo of age was observed in $\mathrm{W}$ versus NW kids (Table 3). Ghirardi et al. (2007) reported $99.4 \%$ retention of B1 boluses in weaned and fattened lambs. Although no losses could be observed in situ in our study, bolus losses by regurgitation have been observed in calves being fed milk from buckets (J. J. Ghirardi, unpublished data).

Regurgitation is recognized to be the main mechanism of bolus losses (Riner et al., 1982; Caja et al., 1999; Garín et al., 2005), although intestinal passage after going through the critical barrier of the reticulo-omasal orifice cannot be discarded, especially when dealing with mini-boluses (Garín et al., 2005; Ghirardi et al., 2007). Studies on slaughtered animals indicate that, at the same BW $(24 \mathrm{~kg})$, the diameter of the reticuloomasal orifice in kids (Martín et al., 2004; $24.0 \mathrm{~mm}$ ) is approximately twice the diameter in lambs (Ghirardi et al., 2007; $14.2 \mathrm{~mm}$ ) and twice the outer diameter of the B1 mini-boluses used (10 mm o.d.). Losses by intestinal passage could be exacerbated in goats if less selective passage through the reticulo-omasal orifice occurs (Katoh et al., 1988; Clauss and Lechner-Doll, 2001). Regarding feeding management, an abrupt diet change may also increase bolus losses (AMLC, 1995; Ghirardi et al., 2007). Garín et al. (2005) found no effect on losses of small size boluses when applied in lambs $1 \mathrm{wk}$ before and after weaning. In our results, no effect on bolus retention could be established with the 2 weaning systems used (60 and $150 \mathrm{~d}$ of age) and after the kids started grazing (4 mo of age).

Losses of B1 bolus started at 2 mo of age (1 mo after administration) whereas the first loss of B2 was registered at $7 \mathrm{mo}$ of age ( $5 \mathrm{mo}$ after administration) which agrees with their features, the B1 being smaller and lighter than B2.

\section{First Year Readability}

Readability after $1 \mathrm{yr}$ of application is considered the key value for the official approval of ID devices in livestock (ICAR, 2007). Devices approved by ICAR must fulfill a readability $>98 \%$. Actual readability values of the different ID devices throughout our study are shown in Table 2. All the visual ear tags readable at mo 5 were retained at 12 mo of age. From them, 1 V1 and 2 V2 showed severe damages caused by biting, but no readability differences between $\mathrm{V} 1$ and $\mathrm{V} 2$ were detected (82.9 vs. $94.0 \%$, respectively; $P=0.107$ ) at the end of the first year, when they were removed. Visual tags did not fulfill the ICAR requirement for official use.

Losses of B1 and B2 mainly occurred during the first year, resulting in a readability numerically greater in B2 than B1 ( $84.6 \%$ vs. $71.4 \%$, respectively; $P=0.182$ ), which was unsatisfactory for official use according to ICAR requirements; no more administrations of $\mathrm{B} 1$ and B2 were performed after being lost. By contrast, the standard-sized B3 used as control device in adult goats were fully readable $(100 \%)$ at the end of yr 1 and are suitable for official use.

No electronic failures or losses were observed for electronic ear tags during the first year of the study, showing $100 \%$ readability and fulfilling the ICAR requirements.

With regard to transponders injected in the distal area of the forefeet, no difference in readability during the first year was detected between T1 and T2 (92.0 vs. $96.0 \% ; P=0.268)$, but their readability values were below the $98 \%$ required for ICAR approval. No breakages or electronic failures were registered at the end of the first year. Most losses of T1 and T2 (90.9\%) occurred during the first $2 \mathrm{wk}$ after injection, similar to results from lambs identified in the same body site with 12-mm transponders (Abecia et al., 2004). These early losses were mainly caused by the backward movement of transponders through the channel of injection before 
the injection wound was totally healed, as observed in other species (Conill et al., 2000; Caja et al., 2005). Furthermore, $98.4 \%$ of T1 and $100 \%$ of T2 losses were registered within 6 mo of injection.

\section{Long-Term Readability of Identification Devices}

Actual readability values of the different ID devices after the first year are shown in Table 2. Bolus losses decreased after the first year and steadied during yr 2 and 3. Readability of B1 was less than B2, although only value at yr 3 differed $(P<0.05)$. No difference between B2 and B3 was detected during the study, although B1 readability was less than that of B3 $(P<$ 0.05). As a consequence, only B3 fulfilled the requested ICAR value for official use.

With regard to electronic ear tags, a total of 3 losses of E2 were registered after the first year; 2 of them during yr 2 and 1 during yr 3 . This last loss was directly observed in the head-locker of the milking parlor during milking, when the male-female mechanism of the ear tag unlocked. No electronic failures were observed for E1 and E2 during the entire study.

During the measurement of the external features of the $\mathrm{F}$ button pieces of $\mathrm{E} 1$ and $\mathrm{E} 2$, which were supposed to be identical, small differences in the internal surface of the coupling orifice were observed between devices. Measurement results showed 2 types of button $\mathrm{F}$ pieces:
$34 \%$ with beveled orifices of $6.7 \pm 0.1 \mathrm{~mm}$, and $64 \%$ with straight orifices of $6.4 \pm 0.0 \mathrm{~mm}(P<0.001)$. The beveled ear tags were able to be manually unlocked by pulling out the male piece (strength required for opening, $9.9 \pm 1.0 \mathrm{~kg}$ ) but not in the straight ones (male pin broke at $30.2 \pm 0.7 \mathrm{~kg}$ ), the difference being significant $(P<0.001)$. According to ICAR $(2007)$, ear tag unfastening force should be greater than 280 $\pm 20 \mathrm{~N}$ (approximately $28.5 \pm 2 \mathrm{~kg}$ ). In addition, a slight difference in the outside diameter of the pin tip of the male piece was also observed in our study, E2 being greater than $\mathrm{E} 1(7.6 \pm 0.01$ vs. $7.5 \pm 0.01 \mathrm{~mm}$, respectively; $P<0.001)$. A negative relationship was established between opening strength of ear tags and the diameter of the orifice of $\mathrm{F}$ piece $(\mathrm{r}=-0.73 ; P<$ $0.001)$.

Because no split ears were observed for E2 losses, we concluded that losses occurred by unlocking the E2 ear tags. Moreover, 3 E2 flag pieces (9.1\%) showed biting damage. Similar damage was also found in 2 E2 that were eventually lost. The use of E1 (button-button) ear tags prevented losses and nibbling.

Injectable transponders showed 1 additional loss of T1 during the second year and readability values ranged from 91 to $96 \%$ (Table 2). No differences were detected between $\mathrm{T} 1$ and $\mathrm{T} 2$, both values being inadequate for official use according to the ICAR requirement. Apart from losses, the main limitation observed for injection

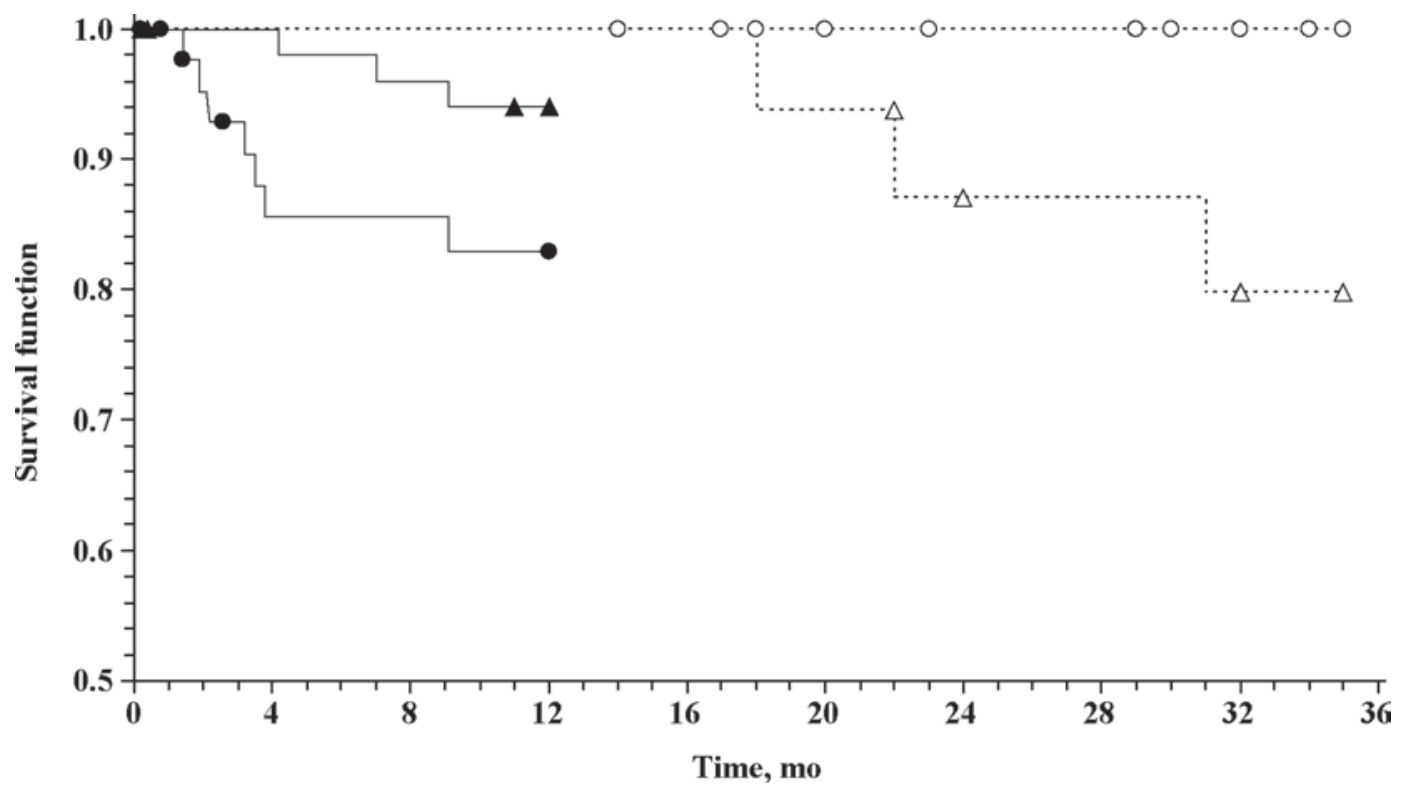

Figure 2. Kaplan-Meier survival distribution functions for visual $(-)$ and electronic ear tags ( $\cdots .$.$) in dairy goats; censored data: V1 (-),$ V2 $(\boldsymbol{\Lambda})$, E1 $(\bigcirc)$, and E2 $(\Delta)$. V1 = tip-tag ear tag (Azasa-Allflex, Madrid, Spain); V2 = official tamper-proof ear tag (Azasa-Allflex); E1 = ear tag made of plastic button male piece (Azasa-Allflex) and electronic button female piece (Allflex Europe, Vitré, France); E2 = ear tag made of plastic flag male piece (Azasa-Allflex) and electronic button female piece (Allflex Europe). 
in the metacarpal area was the lack of room for larger transponders; the use of small transponders results in small reading distances which compromises the efficiency of the recording and monitoring practices. Suitably designed transponders should permit implementation of farm automation; for example, high throughput inventorying, sorting for group or individual treatments, performance recording (weighing, milk recording), feeding according to production. Efficient electronic reading in semi-automated milk recording has proved to reduce labor costs and improve data accuracy in dairy goats (Ait-Saidi et al., 2008). Moreover, another issue when small-sized injectable transponders are used is the difficulty of ensuring that all transponders are removed from carcasses at slaughter.

Long-term readability values estimated by using the Kaplan-Meier nonparametric survival analysis are shown in Figures 2 and 3, and their values are summarized in Table 4. Kaplan-Meier's estimated readabilities were generally lower than actual values, as a consequence of the late losses of ID devices. We considered the Kaplan-Meier's estimates as better indicators of readability because they avoided the bias produced by the low number of animals monitored at long-term (i.e., readability at yr 3 greater than at yr 2). The differences between actual and estimated values at yr 3 averaged $4.1 \%$, ranging between 0 and $6.1 \%$, except in E2, for which the estimated readability was $12.5 \%$ lower than actual. Fosgate et al. (2006) also carried out a 2-yr survival analysis for ear tag retention in water buffalo showing that long-term retention (21.7\% on average) was accurately estimated in both ears by the KaplanMeier's method.

At the end of the study, B3 estimated readability $(96.8 \%)$ was greater $(P<0.05)$ than B1 $(66.3 \%)$ and B2 $(81.4 \%)$ estimates, whereas no difference was detected between $\mathrm{B} 1$ and $\mathrm{B} 2(P=0.126)$. Our results agreed with the readability values previously reported for boluses (JRC, 2003; Capote et al., 2005; Pinna et al., 2006) and confirm the importance of bolus features for assuring their retention and readability in the reticulorumen, not only in cattle and sheep (Caja et al., 1999; Fallon, 2001; Ghirardi et al., 2006) but also in goats (Carné et al., 2007).

The E1 electronic ear tag showed 100\% estimated readability at the end of the $3-y r$ study, which differed $(P=0.022)$ from the E2 estimated readability (79.8\%). Observed E2 late losses as a consequence of aging deterioration is an aspect to be taken into account when comparing the long-term readability of ear tags and some other devices applied internally to the body (bolus and injectable transponders).

Apart from E1 ear tags (100\%), the device with greater readability estimates at the end of the study was the B3 bolus (96.8\%) and no differences could be established $(P>0.05)$ between them. Lower readability

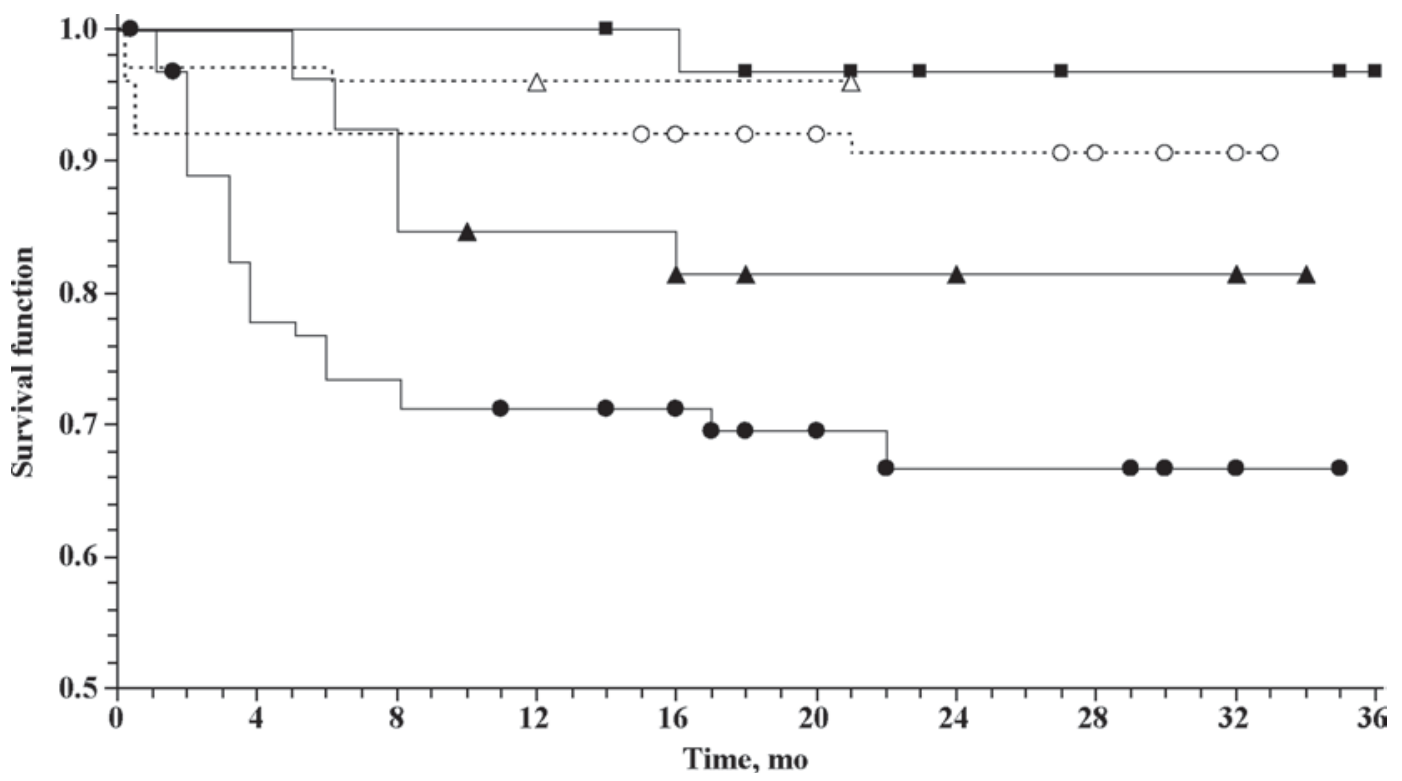

Figure 3. Kaplan-Meier survival distribution functions for electronic ruminal boluses $(-)$ and transponders injected in the forefeet $(\ldots$.$) in$ dairy goats; censored data: B1 $(\bullet)$, B2 $(\mathbf{\Delta})$, B3 $(\mathbf{\square})$, T1 $(\bigcirc)$, and T2 $(\Delta)$. B1 = mini-bolus $13.7 \mathrm{~g}$ and $51.0 \times 10.5 \mathrm{~mm}(\mathrm{Rumitag}$, Esplugues de LLobregat, Spain); B2 = mini-bolus $20.1 \mathrm{~g}$ and $56.4 \times 10.5 \mathrm{~mm}$ (Rumitag); B3 = standard bolus $75 \mathrm{~g}$ and $68.2 \times 21.0 \mathrm{~mm}(\mathrm{Rumitag})$; $\mathrm{T} 1=$ injectable transponder $15 \times 2.1 \mathrm{~mm}$ (Avid Microchip España, Barcelona, Spain); T2 = injectable transponder $12 \times 2.1 \mathrm{~mm}($ Cromasa, Berriozar, Spain). 
Table 4. Readability of identification devices in goats, estimated by Kaplan-Meier nonparametric survival analysis at the end of the study ${ }^{1}$

\begin{tabular}{|c|c|c|c|c|c|c|c|c|c|}
\hline Item & \multicolumn{2}{|c|}{ Visual ear tags } & \multicolumn{3}{|c|}{ Electronic boluses } & \multicolumn{2}{|c|}{ Electronic ear tags } & \multicolumn{2}{|c|}{ Injectable transponders } \\
\hline Devices, $\mathrm{n}$ & 45 & 52 & 92 & 28 & 34 & 46 & 46 & 75 & 100 \\
\hline Censored data, $\mathrm{n}^{2}$ & 38 & 49 & 64 & 23 & 33 & 46 & 43 & 68 & 96 \\
\hline Events, $\mathrm{n}^{3}$ & 7 & 3 & 28 & 5 & 1 & 0 & 3 & 7 & 4 \\
\hline Estimated readability, \% & 83.1 & 94.0 & $66.3^{\mathrm{c}}$ & $81.4^{\mathrm{cd}}$ & $96.8^{\mathrm{ab}}$ & $100^{\mathrm{a}}$ & $79.8^{\text {bd }}$ & $90.4^{\mathrm{bd}}$ & 96.0 \\
\hline
\end{tabular}

${ }^{\mathrm{a}-\mathrm{d}}$ Only for devices monitored until yr 3, values with different superscripts within a row differ $(P<0.05)$.

${ }^{1} \mathrm{~V} 1=$ tip-tag ear tag (Azasa-Allflex, Madrid, Spain); V2 = official tamper-proof ear tag (Azasa-Allflex); B1 = mini-bolus $13.7 \mathrm{~g}$ and $51.0 \times 10.5$ $\mathrm{mm}$ (Rumitag, Esplugues de LLobregat, Spain); B2 = mini-bolus $20.1 \mathrm{~g}$ and $56.4 \times 10.5 \mathrm{~mm}$ (Rumitag); B3= standard bolus $75 \mathrm{~g}$ and $68.2 \times$ $21.0 \mathrm{~mm}$ (Rumitag); E1 = ear tag made of plastic button male piece (Azasa-Allflex) and electronic button female piece (Allflex Europe, Vitré, France); E2 = ear tag made of plastic flag male piece (Azasa-Allflex) and electronic button female piece (Allflex Europe); T1 = injectable transponder $15 \times 2.1 \mathrm{~mm}$ (Avid Microchip España, Barcelona, Spain); T2 = injectable transponder $12 \times 2.1 \mathrm{~mm}$ (Cromasa, Berriozar, Spain).

${ }^{2}$ Devices in which the event was not observed during the study or which left the study earlier than yr 3 .

${ }^{3}$ Devices unreadable.

was estimated for B1 (66.3\%), followed by E2 (79.8\%), B2 $(81.4 \%)$ and T1 (90.4\%), the latter 3 ones not differing $(P>0.05)$.

\section{CONCLUSIONS}

According to our results, electronic ear tags (E1 and E2) and the standard bolus (B3) were the only ID devices that had greater than $98 \%$ readability at 12 mo after application as recommended by the International Committee for Animal Recording (ICAR, 2007) and the Spanish Committee for Animal Electronic Identification (MAPA, 2007).

The use of injectable transponders in the metacarpal area is not recommended in practice because of losses. Physical features of electronic ruminal boluses dramatically affect their retention, and therefore their readability. No differences in bolus retention were detected according to rearing management and feeding. Improvement of electronic bolus retention in goats needs to be achieved before generalizing its use. In contrast to the rest of devices tested, button-button electronic ear tags of appropriate design and technology proved to be efficient devices for goat identification, although because of the small number of animals and devices used in this experiment, we recommend the confirmation of the results on a larger scale.

\section{ACKNOWLEDGMENTS}

This work is part of a research project funded by the Spanish Ministry of Education (Plan Nacional I+D+i; Project AGL-2007-64541). The authors are grateful to Ramon Costa and the team of the Servei de Granges i Camps Experimentals of the Universitat Autònoma de Barcelona (Bellaterra, Spain) for the care of the animals, to Joan F. Vilaseca (Rumitag, Esplugues de
Llobregat, Spain) for advising and providing mini-boluses, to Angel Pardo (Avid-Microchip España, Barcelona., Spain) for providing injectable transponders, to Francisco López-Belmonte (Azasa, Madrid, Spain) for providing electronic ear tags, to Alfred E. Rinaldi III and Jose-Manuel Romero (Tragsega, Madrid, Spain) for injection of transponders, and to Nic Aldam for the English revision of the manuscript.

\section{REFERENCES}

Abecia, J. A., J. A. Valares, F. Forcada, I. Palacín, and L. García 2004. Utilización de unidades electrónicas subcutáneas para la identificación del ganado ovino. Pequeños Rumiantes 5:10-14.

Ait-Saidi, A., G. Caja, S. Carné, A. A. K. Salama, and J. J. Ghirardi. 2008. Comparison of manual vs. semi-automatic milk recording systems in dairy goats. J. Dairy Sci. 91:1438-1442.

Australian Meat and Livestock Corporation (AMLC). 1995. Integration of automated cattle identification with industry management practices. Supplementary report to interim report AMLC.010. Melbourne. Australia.

Caja, G., C. Conill, R. Nehring, and O. Ribó. 1999. Development of a ceramic bolus for the permanent electronic identification of sheep, goat and cattle. Comput. Electron. Agric. 24:45-63.

Caja, G., M. Hernández-Jover, C. Conill, D. Garín, X. Alabern, B. Farriol, and J. Ghirardi. 2005. Use of ear tags and injectable transponders for the identification and traceability of pigs from birth to the end of the slaughter line. J. Anim. Sci. 83:22152224

Cantor, A. B. 2003. SAS Survival Analysis Techniques for Medical Research. 2nd ed. SAS Institute Inc., Cary, NC.

Capote, J., D. Martín, N. Castro, E. Muñoz, J. Lozano, S. Carné, J. J. Ghirardi, and G. Caja. 2005. Retención de bolos ruminales para identificación electrónica en distintas razas de cabras españolas. ITEA Prod. Animal 26(Vol. extra):297-299.

Carné, S., G. Caja, J. J. Ghirardi, and A. A. K. Salama. 2007. Predicting the retention of ruminal boluses for the electronic identification of goats. J. Anim. Sci. 85(Suppl. 1):93. (Abstr.)

Clauss, M., and M. Lechner-Doll. 2001. Differences in selective reticulo-ruminal particle retention as a key factor in ruminant diversification. Oecologia 129:321-327.

Conill, C., G. Caja, R. Nehring, and O. Ribó. 2000. Effects of injection position and transponder size on the performances of passive injectable transponders used for the electronic identification of cattle. J. Anim. Sci. 78:3001-3009. 
Cox, D. R. 1970. The Analysis of Binary Data. Chapman \& Hall, London, UK.

Daza, A. 2004. Sistemas de produccion. Pages 73-88 in Ganado Caprino. Producción, Alimentación y Sanidad. A. Daza, C. Fernández, and A. Sánchez, ed. Editorial Agrícola Española, Madrid, Spain.

Edwards, D. S., A. M. Johnston, and D. U. Pfeiffer. 2001. A comparison of commonly used ear tags on the ear damage of sheep. Anim. Welf. 10:141-151

Fallon, R. J. 2001. The development and use of electronic ruminal boluses as vehicle for bovine identification. Rev. Sci. Tech. Off. Int. Epizoot. 20:480-490.

Fosgate, G. T., A. A. Adesiyun, and D. W. Hird. 2006. Ear-tag retention and identification methods for extensively managed water buffalo (Bubalus bubalis) in Trinidad. Prev. Vet. Med. 73:287-296.

Garín, D., G. Caja, and C. Conill. 2005. Performance and effects of small ruminal boluses for electronic identification of young lambs. Livest. Prod. Sci. 92:47-58.

Ghirardi, J. J., G. Caja, C. Flores, D. Garín, M. Hernández-Jover, and F. Bocquier. 2007. Suitability of electronic mini-boluses for early identification of lambs. J. Anim. Sci. 85:248-257.

Ghirardi, J. J., G. Caja, D. Garín, J. Casellas, and M. HernándezJover. 2006. Evaluation of the retention of electronic identification boluses in the forestomachs of cattle. J. Anim. Sci. 84:22602268.

International Committee for Animal Recording (ICAR). 2007. International Agreement of Recording Practices. Guidelines approved by the General Assembly held in Kuopio, Finland, June 2006, International Committee for Animal Recording. Rome, Italy.

International Committee for Animal Recording (ICAR). 2008. Animal Identification: List of Manufacturer Codes. Available: http://www. service-icar.com/Manufacturers_DB/manufacturer_codes_main. asp Accessed Aug. 23, 2008

International Organization for Standardization (ISO). 1996a. Agricultural Equipment. Radio-Frequency Identification of
Animals - Code Structure. ISO 11784:1996 (E). 2nd ed. Geneva, Switzerland.

International Organization for Standardization (ISO). 1996b. Agricultural Equipment. Radio-Frequency Identification of Animals - Technical Concept. ISO 11785:1996 (E). 2nd ed. Geneva, Switzerland.

Joint Research Center (JRC). 2003. IDEA Project, large scale project on livestock electronic identification. Final Report. v. 5.2 Available: http://idea.jrc.it/pages\%20idea/ final\%20report.htm Accessed Mar. 30, 2008.

Katoh, K., F. Sato, A. Yamazaki, Y. Sasaki, and T. Tsuda. 1988. Passage of indigestible particles of various specific gravities in sheep and goats. Br. J. Nutr. 60:683-687.

Kleinbaum, D. G., and M. Klein. 2005. Survival Analysis: A SelfLearning Text (Statistics for Biology and Health). 2nd ed. Springer, New York, NY.

Martín, D., J. Capote, J. Sicilia, A. Castro, and J. L. López. 2004. Efecto de la identificación electrónica con bolo ruminal en los parámetros de crecimiento y de desarrollo de los estómagos de cabritos. Pages 86-87 in XXIX Jornadas Científicas de la SEOC, Lleida, Spain.

Ministerio de Agricultura, Pesca y Alimentación (MAPA). 2007. Identificación Electrónica Animal: Experiencias del MAPA. MAPA, Madrid, Spain.

Ørskov, E. R., D. Benzie, and R. N. B. Kay. 1970. The effects of feeding procedure on closure of the oesophageal groove in young sheep. Br. J. Nutr. 24:785-794.

Pinna, W., P. Sedda, G. Moniello, and O. Ribó. 2006. Electronic identification of Sarda goats under extensive conditions in the island of Sardinia. Small Rumin. Res. 66:286-290.

Riner, J. L., R. L. Byford, L. G. Stratton, and J. A. Hair. 1982 Influence of density and location on degradation of sustainedrelease boluses given to cattle. Am. J. Vet. Res. 43:2028-2030. 